\title{
Maximum respiratory pressures: values found and predicted in children
}

\begin{abstract}
Objective: To develop predictive equations for respiratory muscle strength (RMS) in 5 to 10 year old children.

Materials and methods: This was a cross-sectional study in which 148 children took part, including boys and girls between 5 and 10years of age. They were evaluated using a respiratory disease questionnaire validated for Brazil, and then submitted to a spirometric and anthropometric evaluation. The RMS measurements were obtained by manovacuometry and consisted of the maximum respiratory pressures. All the evaluations were carried out on the same day by the same evaluator.
\end{abstract}

Results: The predictive power of the equations $\left(R_{2}\right)$ was between 25 and $63 \%$, and by applying Pearson's correlation test it was shown that the MIP and MEP of the boys and girls presented significant correlation with age, height and body mass. Thus the mathematical models were separated according to gender and the results submitted to multiple linear regression. A Bland-Altman visual analysis was also used to evaluate agreement between the proposed predictive values and those of other already existing MIP and MEP equations.

Conclusion: The equations giving predictive values for the MIP and MEP in 5 to 10year old children were shown to be reproducible.

Keywords: respiratory muscle strength, predictive equations, reference values
Volume I Issue 3 - 2014

\author{
Evelim Leal de Freitas Dantas Gomes,' \\ Fabiana Sobral Peixoto-Souza, ${ }^{2}$ Etiene Farah \\ Teixeira de Carvalho, ${ }^{2}$ Eloisa Sanches Pereira \\ do Nascimento, ${ }^{3}$ Luciana Maria Malosa \\ Sampaio, ${ }^{4}$ Jonatas Silva Eloi, ${ }^{5}$ Acássia Fonseca \\ de Magalhães, ${ }^{5}$ Dirceu Costa ${ }^{4}$ \\ 'Doctor in Rehabilitation Sciences from the Nove de Julho \\ University (UNINOVE), Brazil \\ ${ }^{2}$ Doctorate student in the Rehabilitation Sciences Postgraduate \\ Program of the Nove de Julho University (UNINOVE), Brazil \\ ${ }^{3}$ Master in Rehabilitation Sciences from the Nove de Julho \\ University (UNINOVE), Brazil \\ ${ }^{4}$ Rehabilitation Sciences Postgraduate Program of the Nove de \\ Julho University (UNINOVE), Brazil \\ ${ }^{5}$ Physiotherapist, Nove de Julho University (UNINOVE), Brazil
}

Correspondence: Evelim Leal de Freitas Dantas Gomes, LARESP. Rua:Vergueiro, 235/249, 2SS. Master's and doctorate in Rehabilitation Sciences - Liberdade, São Paulo - SP, CEP: 01504 00 I Brazil, Tel +55- I I-3385-924 I, Fax +55- I I-3385-924 I, Email evelimfreitas@hotmail.com
Abbreviations: MIP, maximum inspiratory pressure; MEP, maximum expiratory pressure; RMS, respiratory muscle strength; FVC, forced vital capacity; RV, residual volume; TPC, total pulmonary capacity; ATS, American thoracic society

\section{Introduction}

The respiratory muscle strength (RMS) has been measured by way of pressures generated by the respiratory muscles and measured in the mouth against an occluded via connected to an equipment known as a manovacuometer. In the inspiratory phase the maximum inspiratory pressure (MIP) is measured, which translates the strength of the inspiratory muscles, and in the expiratory phase, the maximum expiratory pressure is measured (MEP), which translates the strength of the expiratory muscles. This measurement is commonly used to detect any possible weakness of these muscles, as well as quantifying and providing auxiliary information about the seriousness of any possible respiratory diseases. ${ }^{1,2}$ The evaluation of MIP and MEP is of great importance in children, especially in those suffering from chronic respiratory diseases such as asthma and cystic fibrosis, and also from certain neuromuscular diseases which could lead to debility of the respiratory muscles. ${ }^{3}$ Although little exploited in children, the RMS is of fundamental importance in the process of weaning from mechanical ventilation in intensive care units, which already occurs regularly with the adult and aged populations. ${ }^{4}$ The RMS has also been employed to evaluate the evolution of rehabilitative interventions, especially in respiratory muscular strength training, both with mechanical devices and with physical exercise. ${ }^{5}$
Thus exploitation of the predictive values for MIP and MEP, still incipient in the infant population, could be reproducible and contribute to delving deeper into an exploration of reference data, and to aid in providing parameters for therapeutic procedures, especially those involving respiratory muscles.

There are various predictive equations for the MIP and MEP of adult populations, ${ }^{6}$ normally proposed for each decade of life, whereas for children they involve the pre-school and school age ranges, including different ages and also those of adolescents. Since this age range covers considerable and rapid changes in stature, also showing differences between genders, rapid changes in respiratory muscle strength may also occur, requiring equations that can explore the ages with greater particularity, if possible, year by year as the child grows.

Hence the exploration of RMS using more restricted age ranges could contribute to a greater elucidation of the predictive values for MIP and MEP in children. Thus the objective of this study was to develop predictive equations for the RMS in 5 to 10year old children.

\section{Methods}

\section{Population studied}

This was a cross-sectional study in which 148 five to ten year old children of both sexes took part. The study was approved by the Ethics in Research Committee of the Nove de Julho University (UNINOVE), report $n^{\circ} 69799 / 2012$. The respective legal representatives of the children evaluated read and signed a Free and Clarified Term of consent before the evaluations. 
The children were separated and evaluated in a junior and secondary school located in the city of São Paulo, Brazil, which complied with the following requisites: full time functioning with more than 300 students in a middle class suburb, with equilibrated numbers of boys and girls matriculated. The data were collected during the period from September to November of 2012 with the due approval of the Secretariat of Education of the City of São Paulo and agreement of the School Director.

The following inclusion criteria were adopted: healthy children from a respiratory point of view, analyzed by way of a questionnaire about respiratory diseases (ATS-DLD-78-C), adapted and validated for use in Brazil by pediatric pulmonologists. ${ }^{7}$ The questionnaire was composed of 9 questions referring to respiratory symptoms, and a score equal or higher than 7 excluded the child from the evaluation. Another important question for inclusion was the absence of any type of ventilatory disturbance as verified using a spirometer (Easy One plus NDD ${ }^{\mathrm{TM}}$ portable spirometer, Andover, MA, USA), that is forced vital capacity (FVC), expiratory volume in the first second (FEV1) and a FEV1/FVC ratio above $80 \%$, the predicted values used being those of Polgar et al. ${ }^{8}$ The reproducibility of the maneuvers and values were provided by the spirometer software, classified as of levels A and $\mathrm{B}$, with a minimum of 6 seconds duration, only the best values being consisted in computing the data in agreement with the American Thoracic Society (ATS). ${ }^{1,9}$

The following exclusion criteria were adopted: premature-born children $(<37$ weeks), low birth weight $(<2,500 \mathrm{~g})$, heart disease, neuromuscular disease, presence of alterations in the thoracic and/or abdominal regions that altered the respiratory dynamics, and a lack of understanding of how to carry out the tests. ${ }^{1,9}$

The following exclusion criteria were adopted: premature-born children $(<37$ weeks), low birth weight $(<2,500 \mathrm{~g})$, heart disease, neuromuscular disease, presence of alterations in the thoracic and/or abdominal regions that altered the respiratory dynamics, and a lack of understanding of how to carry out the tests. ${ }^{1,9}$

The sample size was determined based on previous studies ${ }^{10,11}$ in which 15 to 20 subjects were studied per age range, with equal distribution between the genders. Thus a sample number $(\mathrm{N})$ of 15 to 20 children was established for each gender and each age in the range between 5 and 10. Based on this, the minimal sample size was of 120 children, but to guarantee a good safety margin, after attending all the inclusion and exclusion criteria, 148 of the 162 selected children were evaluated and considered for the calculation of the equations for the predictive values of MIP and MEP.

\section{Anthropometric evaluation}

The children remained in a standing position with no shoes and no heavy clothing. The body weight was obtained using a duly calibrated digital balance (Filizola ${ }^{\circledR}$, Brazil) with a maximum capacity for $300 \mathrm{Kg}$ and resolution of $100 \mathrm{~g}$, and the height using a wall stadiometer (Wiso) with resolution in millimeters. The BMI was calculated from the equation weight/stature $2\left(\mathrm{Kg} / \mathrm{m}^{2}\right)$. The Anthro plus program was used which applies the World Health Organization (WHO) standards in z-scores. The BMI z-score was used to classify the children as obese or eutrophic. Values between +2 and -2 were considered for eutrophic children. ${ }^{12}$

\section{Evaluation of the maximum respiratory pressures}

A previously calibrated analogical manovacuometer ${ }^{13}$ with an operational interval between 0 and $\pm 300 \mathrm{~cm} \mathrm{H}_{2} \mathrm{O}$ and equipped with an air escape valve was used to measure MIP and MEP. The children were first shown how to carry out the tests correctly, keeping their lips firmly sealed shut to prevent the escape of air [14].

MIP was measured during maximum inspiration at the level of the total pulmonary capacity (TPC), with inspirations as from the level of the Residual volume (RV). In order to avoid perioral leakage, the children were oriented to compress their cheeks. The position reached at the end of the maximum efforts was maintained for at least 1 second to characterize the plateau pressure. ${ }^{14}$ The children were oriented to remain seated with their feet supported and using a nasal clip.

All the children carried out at least three maximum inspirations and expiration efforts, with an interval of 1 minute between each one. ${ }^{6}$ They were all technically acceptable and reproducible, that is with no leakage of the perioral air, sustained for at least 1 second and with similar values for the three efforts ( $\leq 10 \%$ between them). If a higher value was obtained for the last maneuver, the test was continued until a closer value was obtained, with a difference of $\leq 10 \%$. In such cases the number of maneuvers would be more than three, but should not pass five. For the data analysis the highest value was registered. ${ }^{6,15}$

\section{Statistical analysis}

The data distribution was verified using the Shapiro-Wilk test, and after confirming normality, they were expressed as the mean plus standard deviation for the comparison of the anthropometric data and spirometric variables of the children, according to gender and age.

The Student $t$ test was applied to compare the values obtained for MIP and MEP with the respective predicted values obtained using the different equations. The ANOVA test was used for repeated measurements with the Bonferroni post-hoc for MIP and MEP.

The correlation test was applied between the predicted values and those obtained for respiratory muscular strength. The association between the values obtained for MIP and MEP with potential predictive variables (gender, age, stature and body mass) was evaluated by multiple linear regressions. The Bland-Altman visual analysis was used to evaluate any lack of agreement between the values obtained and those predicted by the new equation in the prediction of normality for the RMS in children.

All the statistical procedures were carried out using the BioStat statistical program, version 5.0, and Medcalc, version 12.2.1 (MedCal Software, Mariakerke, Belgium) and the level of statistical significance adopted was of $\mathrm{p}<0.05$.

\section{Results}

Of the 162 children selected, 14 were excluded for the following reasons: two due to respiratory infections; four because they did not manage to carry out all the tests; three because they did not present the term of consent signed by the person responsible; and five because they presented altered spirometric values. Thus 148 children made up the final sample distributed amongst the ages from five to tenyears old, as shown in Table 1. There was no significant difference in the anthropometric and spirometric characteristics for each age and gender in the children under study.

With respect to the values obtained for MIP, it was shown that 9 -year old boys presented significantly higher values than girls of the same age. On the other hand, 5-year old girls presented significantly higher values for MEP than boys of the same age. As can be seen in Table 2, it was observed that for both MIP and MEP and for both boys and girls, there was a significant increase as from 7 years of age. 
However, on considering the means of all the values, it must be noted that the values for MIP and MEP were always higher for boys than for girls.

Table 3 shows that when the values obtained were compared with those based on the equations proposed by Wilson, et al., ${ }^{3}$ no significant differences were found in the values for MIP for either the boys or the girls or in the values for MEP for the girls. However, significant differences were found between the values obtained and those predicted by the equations proposed by Heinzmann-Filho et al. ${ }^{16}$

By applying Pearson's correlation test with $\mathrm{p}<0.0001$, it was found that the MIP for the girls presented significant correlation with age $(\mathrm{r}=0.54)$, stature $(\mathrm{r}=0.4313)$ and body mass $(\mathrm{r}=0.4273)$, whereas for the boys, it presented significant correlation with age $(\mathrm{r}=0.5738)$, stature $(r=0.6252)$ and body mass $(r=0.5517)$. On the other hand, MEP presented significant correlation with age $(\mathrm{r}=0.5389)$, stature $(\mathrm{r}=0.5185)$ and body mass $(\mathrm{r}=0.4353)$ for the girls, whereas for the boys, it presented significant correlation with age $(\mathrm{r}=0.3642)$, stature $(\mathrm{r}=0.3979)$ and body mass $(\mathrm{r}=0.3642)$.
Thus the children were separated by gender and tested by way of multiple linear regressions, providing the following equations to predict the values for respiratory muscle strength, as shown in Frame 1 .

The results of the graphical statistical analysis carried out by the Bland-Altman test to show differences between the values obtained and those predicted by the proposed equation showed the following: there was no difference for MIP $\left(0.0 \mathrm{~cm} \mathrm{H}_{2} \mathrm{O}\right)$ with an interval of confidence from -35.9 to $35.9 \mathrm{~cm} \mathrm{H}_{2} \mathrm{O}$; and there was a mean difference for MEP of $-2.1 \mathrm{~cm} \mathrm{H}_{2} \mathrm{O}$ with an interval of confidence from -9.2 to $24.9 \mathrm{~cm} \mathrm{H}_{2} \mathrm{O}$.

For the MIP of the equation proposed by Wilson et al., ${ }^{3}$ the graphical analysis showed a mean difference of -0.3 and an interval of confidence from -38.5 to $39.2 \mathrm{~cm} \mathrm{H}_{2} \mathrm{O}$, and for the MEP a mean difference of -2.5 and an interval of confidence from -31.7 to $26.7 \mathrm{~cm}$ $\mathrm{H}_{2} \mathrm{O}$. For the MIP of the equation proposed by Heizmann-Filho et al., ${ }^{16}$ the graphical analysis showed a mean difference of -19.4 and an interval of confidence from -56 to $17.2 \mathrm{~cm} \mathrm{H} \mathrm{H}_{2} \mathrm{O}$, and for the MEP a mean difference of -28.7 and an interval of confidence from -68 to $2.7 \mathrm{~cm} \mathrm{H}_{2} \mathrm{O}$ (Figure 1).

Table I Anthropometric characteristics and spirometric variables of the children according to gender and age

\begin{tabular}{lllllll}
\hline & $\begin{array}{l}\mathbf{5 y e a r s} \\
\mathbf{n = 3 0}\end{array}$ & $\begin{array}{l}\mathbf{6 y e a r s} \\
\mathbf{n = 1 8}\end{array}$ & $\begin{array}{l}\mathbf{7 y e a r s} \\
\mathbf{n = 2 7}\end{array}$ & $\begin{array}{l}\mathbf{8 y e a r s} \\
\mathbf{n = 2 8}\end{array}$ & $\begin{array}{l}\mathbf{9 y e a r s} \\
\mathbf{n = 2 8}\end{array}$ & $\begin{array}{l}\text { 10years } \\
\mathbf{n = 1 7}\end{array}$ \\
\hline Male & & & & & & \\
Body Mass (Kg) & $20.45 \pm 4.41$ & $25.8 \pm 4.17$ & $26.05 \pm 3.30$ & $32.33 \pm 3.71$ & $35.16 \pm 7.94$ & $38.03 \pm 8.55$ \\
BMI (Kg/m $)$ & $16.34 \pm 2.62$ & $16.37 \pm 2.11$ & $16.63 \pm 2.23$ & $17.83 \pm 1.86$ & $18.72 \pm 3.94$ & $18.09 \pm 3.12$ \\
Z Score Weight & $0.78 \pm 1.43$ & $1.17 \pm 1.00$ & $2 \pm 1.39$ & $1.51 \pm 0.67$ & $1.32 \pm 1.18$ & $0.91 \pm 1.22$ \\
Stature (m) & $1.13 \pm 0.05$ & $1.25 \pm 0.03$ & $1.25 \pm 0.04$ & $1.34 \pm 0.03$ & $1.39 \pm 0.05$ & $1.44 \pm 0.06$ \\
Z-Score Stature & $0.60 \pm 1.28$ & $1.54 \pm 1.12$ & $1.23 \pm 0.99$ & $1.29 \pm 0.53$ & $1.06 \pm 0.86$ & $0.77 \pm 0.90$ \\
FVC (\%P) & $122 \pm 10.3$ & $116 \pm 12.8$ & $93 \pm 15.08$ & $108 \pm 9.7$ & $112 \pm 10.6$ & $104 \pm 9.5$ \\
FEV (\%P) & $95 \pm 10.8$ & $96 \pm 9.7$ & $83 \pm 11.9$ & $97 \pm 10.9$ & $101 \pm 9.7$ & $94 \pm 9.6$ \\
FEV /FVC (\%P) & $93 \pm 5.7$ & $85 \pm 4.3$ & $101 \pm 3.7$ & $90 \pm 5$ & $90 \pm 5.3$ & $90 \pm 4.8$ \\
Female & & & & & & \\
Body Mass (Kg) & $20.04 \pm 4.22$ & $23.82 \pm 4.21$ & $26.35 \pm 3.35$ & $30.12 \pm 8.52$ & $34.81 \pm 11.84$ & $40.75 \pm 11.84$ \\
BMI (Kg/m2) & $15.71 \pm 2.41$ & $15.90 \pm 2.26$ & $16.65 \pm 2.14$ & $18.57 \pm 4.04$ & $18.61 \pm 3.70$ & $19.67 \pm 4.65$ \\
Z-Score Weight & $0.80 \pm 1.40$ & $0.95 \pm 1.00$ & $1.52 \pm 1.26$ & $1.41 \pm 1.15$ & $1.13 \pm 1.15$ & $1.72 \pm 1.36$ \\
Stature (m) & $1.12 \pm 0.07$ & $1.22 \pm 0.06$ & $1.25 \pm 0.04$ & $1.33 \pm 0.05$ & $1.36 \pm 0.05$ & $1.47 \pm 0.05$ \\
Z-Score Stature & $0.70 \pm 1.48$ & $1.39 \pm 1.32$ & $1.08 \pm 0.89$ & $1.18 \pm 0.81$ & $0.81 \pm 0.93$ & $1.14 \pm 1.02$ \\
FVC (\%P) & $101 \pm 10.8$ & $134 \pm 7.8$ & $122 \pm 8.7$ & $116 \pm 10.4$ & $94 \pm 15.08$ & $114 \pm 12.7$ \\
FEV, (\%P) & $99 \pm 10.9$ & $124 \pm 10.5$ & $101 \pm 11$ & $101 \pm 10.7$ & $95 \pm 10.5$ & $102 \pm 9.8$ \\
FEV,/FVC (\%P) & $98 \pm 4.3$ & $93 \pm 3.7$ & $85 \pm 6.3$ & $93 \pm 5.3$ & $101 \pm 4.8$ & $89 \pm 4.5$ \\
\hline
\end{tabular}

Values expressed as the mean \pm standard deviation. BMI, body mass index; FVC (\%P), forced vital capacity as a percentage of the predicted values; FEV /FVC (\%P), ratio $F E V, / F V C$ as a percentage of the predicted value. $Z$ score $\leq 2$ and $\geq-2$

Table 2 Mean of the maximum respiratory pressures according to gender and age

\begin{tabular}{lllllll}
\hline & 5years & 6years & 7years & 8years & 9years & 10years \\
\hline Male & & & & & & \\
MIP $\left(\mathrm{cm} \mathrm{H}_{2} \mathrm{O}\right)$ & $46.36 \pm \mid 4.33$ & $63.33 \pm 30.11$ & $65.00 \pm 17.86$ & $64.5 \pm|4.6|$ & $88.33 \pm 16.96 *$ & $80.66 \pm 21.53$ \\
MEP $\left(\mathrm{cm} \mathrm{H}_{2} \mathrm{O}\right)$ & $42.10 \pm \mid 4.74$ & $51.81 \pm 21.36$ & $56.15 \pm 17.09$ & $61.66 \pm 18.55$ & $68.12 \pm 22.27$ & $65.00 \pm 26.45$ \\
\hline
\end{tabular}


Table Continued..

\begin{tabular}{lllllll}
\hline & 5years & 6years & 7years & 8years & 9years & 10years \\
Female & & & & & & \\
MIP $\left(\mathrm{cm} \mathrm{H} \mathrm{H}_{2} \mathrm{O}\right)$ & $43.68 \pm 13.82$ & $47.27 \pm 13.48$ & $68.46 \pm 16.25$ & $66.11 \pm 17.86$ & $67.5 \pm 15.27$ & $67.5 \pm 12.27$ \\
$\mathrm{MEP}\left(\mathrm{cm} \mathrm{H}_{2} \mathrm{O}\right)$ & $56.36 \pm 17.47 *$ & $55 \pm 25.09$ & $65.00 \pm 15.06$ & $70.5 \pm 30.59$ & $90 \pm 23.74$ & $79.33 \pm 15.79$ \\
\hline
\end{tabular}

*Significant difference between the values obtained for boys and girls $(p<0.05)$

Table 3 Values for MIP and MEP obtained and predicted by the Wilson and Heinzmann-Filho equations

\begin{tabular}{|c|c|c|c|c|c|c|}
\hline & 5years & 6years & 7years & $8 y e a r s$ & $9 y e a r s$ & IOyears \\
\hline \multicolumn{7}{|l|}{ Male } \\
\hline MIP $\left(\mathrm{cm} \mathrm{H}_{2} \mathrm{O}\right)$ & $46.36 \pm 14.33$ & $63.33 \pm 30.11$ & $65.00 \pm 17.86$ & $64.5 \pm|4.6|$ & $88.33 \pm 16.96 *$ & $80.66 \pm 21.53$ \\
\hline $\operatorname{MEP}\left(\mathrm{cm} \mathrm{H}_{2} \mathrm{O}\right)$ & $42.10 \pm 14.74$ & $5 I .8 I \pm 21.36$ & $56.15 \pm 17.09$ & $61.66 \pm 18.55$ & $68.12 \pm 22.27$ & $65.00 \pm 26.45$ \\
\hline \multicolumn{7}{|l|}{ Female } \\
\hline MIP $\left(\mathrm{cm} \mathrm{H}_{2} \mathrm{O}\right)$ & $43.68 \pm \mid 3.82$ & $47.27 \pm 13.48$ & $68.46 \pm 16.25$ & $66.11 \pm 17.86$ & $67.5 \pm 15.27$ & $67.5 \pm 12.27$ \\
\hline $\operatorname{MEP}\left(\mathrm{cm} \mathrm{H}_{2} \mathrm{O}\right)$ & $56.36 \pm 17.47^{*}$ & $55 \pm 25.09$ & $65.00 \pm 15.06$ & $70.5 \pm 30.59$ & $90 \pm 23.74$ & $79.33 \pm 15.79$ \\
\hline
\end{tabular}

Values expressed as the mean \pm standard deviation. EWilson: equation proposed by Wilson et al.2, I984, E Heinzmann-Filho: equation proposed by HeinzmannFilho et al. ${ }^{16} *$ p $<0.05$ statistically significant between the values obtained and those predicted; PImax, maximum inspiratory pressures; PEmax, maximum expiratory pressures
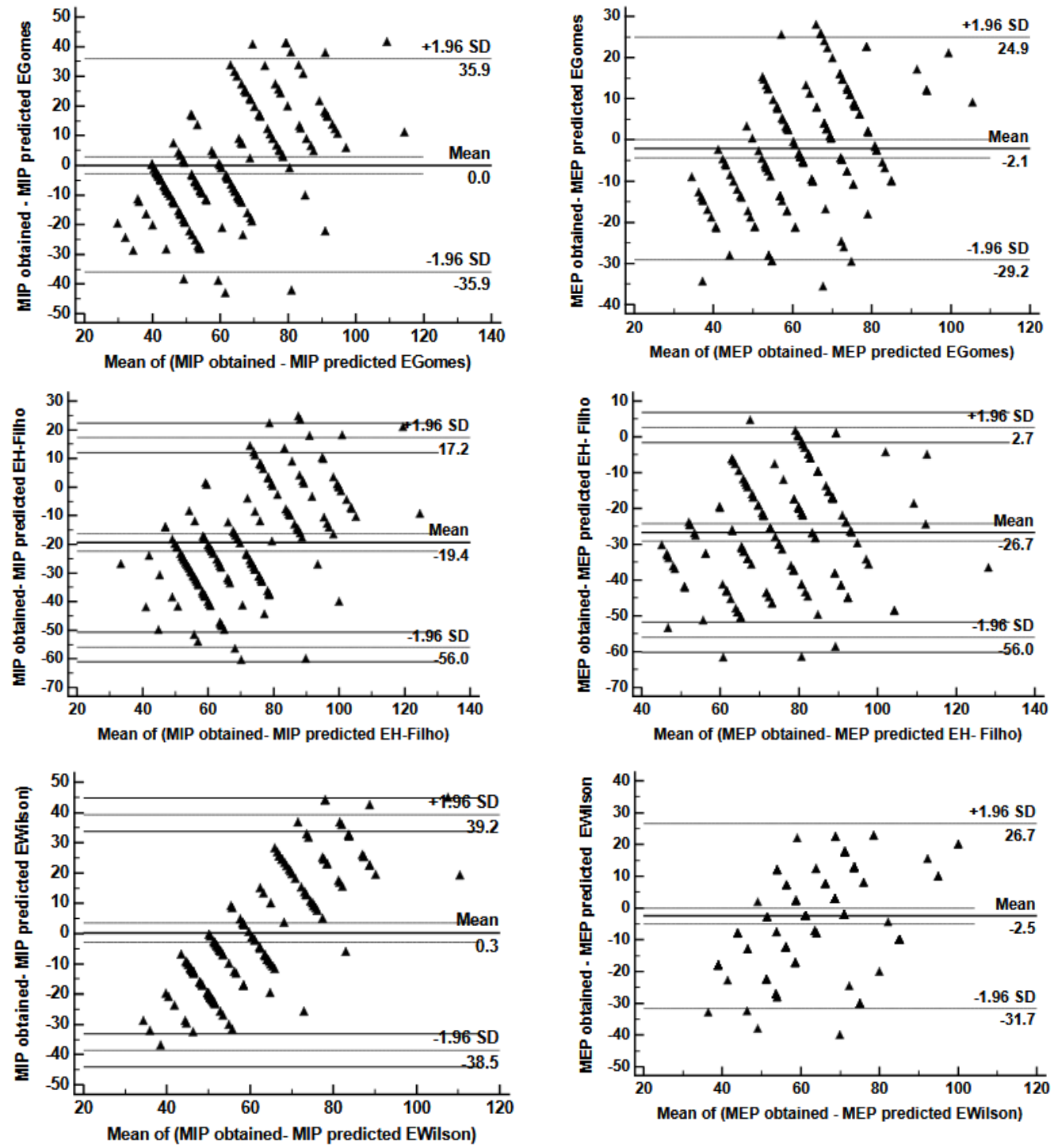

Figure I Bland altmann plot. 
Frame I Predictive equations for the values of MIP and MEP in 5 to 10 year old boys and girls.

\section{MIP (cm $\mathrm{H}_{2}$ O)}

Boys: $-62.2+1.26$ xage +0.50 xbody mass +80.1 xstature

( $R^{2}$ adjusted $=0.63$ )

Girls: $7.31+3.2 x a g e+0.47 x$ body mass $+9.7 x$ stature

( $R^{2}$ adjusted $=0.48$ )

MEP $\left(\mathrm{cm} \mathrm{H}_{2}\right.$ O)

Boys: $49.6+7,23$ xage $+0.47 x$ body mass $+(-37.3$ xstature $)$

( $R^{2}$ adjusted $\left.=0.25\right)$

Girls: $-10.8+4.05 x$ age $+0.08 x$ body mas $+30.4 x$ stature

( $R^{2}$ adjusted $\left.=0.55\right)$

\section{Discussion}

For both genders, correlation was found between the RMS and body mass, age and stature, and after multiple linear regressions, the formulas included the three variables for the calculation of the equations for the predicted values for RMS for the age range under study. The initial hypothesis that the evaluation of this variable carried out with restricted age ranges, considering the measurements per age (year by year), could provide useful information about this parameter, better elucidating the values for MIP and MEP in 5 to 10year old children, was confirmed by the equations generated in this study. In addition it was possible to explore these variables in children in a previously unexplored region of Brazil.

Despite the unquestionable contribution of these results, one must recognize certain limitations of this study, especially the restricted regional area used to obtain the sample, which could, in a certain way, explain the differences found using the equations of HeizmannFilho et al., ${ }^{16}$ who evaluated children in the southern region of the country. Another limiting factor was the non-evaluation of the body composition of the children, considering reports concerning the influence of lean mass in increasing the strength of the respiratory muscles. ${ }^{17}$

The need to explore increasingly restricted age ranges should be pointed out, especially between infancy and adolescence, due to the influence exerted by great alterations in the physique, common in this stage of growth. Wilson et al., ${ }^{3}$ found that body mass was the determinant variable for MIP for both genders, and age for MEP, in a sample varying from 7 to 18 years of age. Domenech-Clar et al., ${ }^{18}$ also used the variables of age, stature and body mass to predict the RMS, with the exception of MEP in girls, where they only used the variable of age. In addition these authors ${ }^{18}$ only included children and adolescents from 8 to 17 years old, an age range that does not cover pre-school children. With such characteristics, the predictive equations proposed by these authors might be more appropriate for adolescents.

Heinzmann-Filho et al., ${ }^{16}$ evaluated 171 four to twelveyear old Brazilian children in the south of the country, and found that the MIP for both genders was influenced by stature and body mass whereas the MEP was influenced by age and body mass. This was the first study ${ }^{16}$ that showed values of normality for children below sixyears of age, and the first study to demonstrate the RMS in Brazilian children and adolescents. Since Brazil is a country with many regional differences, this justifies further studies with children from different geographical regions of the country, to better elucidate the predictive values for RMS.

The main reason for having opted for an even more restricted age range than that of Heinzmann-Filho et al., ${ }^{16}$ the only study on the Brazilian population found up to the present moment, and study children up to a maximum of 10years of age, was that the changes presumably occurring up to physiological maturity are influenced by sexual hormones, which can interfere directly or indirectly with the respiratory muscle strength..$^{19,20}$ The literature shows that, as with other skeletal muscles, many factors contribute to an improvement in strength and resistance of the respiratory muscles, and consequently increase the maximum respiratory pressures. ${ }^{18}$ These factors include the increase in size of the muscle with body growth, the maturation of neural influence ${ }^{21}$ and the anabolic effect of testosterone. ${ }^{21,22}$ Thus the principle factor amongst those cited that could explain the change in respiratory pressure with age in this study, could be the increase in the anthropometric values, especially that of lean mass, which reflects the increase in respiratory muscle..$^{19,21}$

Studies have shown that the respiratory muscle strength is greater in the male gender. ${ }^{2,18}$ However the present results showed that only in 9 year old boys were the values for MIP significantly higher, probably because the differences between the male and female genders start to appear at this age.

With the objective of providing greater sustainability to the results obtained, especially to the proposed predictive equations, the BlandAltman visual analyses were applied, so that the degree of agreement between the values obtained and those predicted by the Wilson et al. 1984 and Heinzmann-Filho et al., ${ }^{16}$ equations could be observed. It was shown that the equations suggested by Wilson et al. 1984 were those showing less lack of agreement with the values obtained for RMS in the children studied.

The importance of obtaining predictive values for MIP and MEP must be underlined, in order to provide a foundation and be able to accompany the advances in life support technologies in pediatric intensive care, in the diagnosis of neuromuscular diseases and in the survival of children with chronic respiratory diseases. The RMS may be reduced in various situations, such as in children ventilated for prolonged periods, in post-operative situations with damage to the phrenic nerve, post sepsis, corticoid therapy and, as cited above, in chronic diseases. Weakness of the inspiratory muscles is characterized by a ventilatory deficit and weakness of the expiratory muscles, with an inefficient or little efficient cough.

Such clinical observations reinforce the need for constant and improved explorations into the measurements of MIP and MEP, aiming at consensus and standardization of this method so widely used in the evaluation of respiratory function in children. ${ }^{23-27}$

\section{Conclusion}

According to the results obtained, it was concluded that the equations providing predictive values for MIP and MEP in 5 to 10year old children, taking age, stature and body mass into consideration, could be useful in predicting the RMS of this population.

\section{Acknowledgements}

None. 


\section{Conflict of interest}

The author declares no conflict of interest.

\section{References}

1. American Thoracic Society. Standardization of spirometry 1994 update. Am J Respir Crit Care Med. 1995;152:1107-1136.

2. Tomalak W, Pogorzelski A, Prusak J. Normal values for maximal static inspiratory and expiratory pressures in healthy children. Pediatr Pulmonol. 2002;34(1):42-46.

3. Wilson SH, Cooke NT, Edwards RH, et al. Predicted normal values for maximal respiratory pressures in caucasian adults and children. Thorax. 1984;39(7):535-538.

4. Cader SA, de Souza Vale RG, Zamora VE, et al. Extubation process in bed-ridden elderly intensive care patients receiving inspiratory muscle training:a randomized clinical trial. Clin Interv Aging. 2012;7:437443

5. Martin AD, Smith BK, Davenport PD, et al. Inspiratory muscle strength training improves weaning outcome in failure to wean patients:a randomized trial. Crit Care. 2011;15(2):R84.

6. Neder JA, Andreoni S, Lerario MC, et al. Reference values for lung function tests. II. Maximal respiratory pressures and voluntary ventilation. Braz J Med Biol Res. 1999;32(6):719-727.

7. Esteves ASD, Ferraz M. Adaptation and validity of the ATSDLD- 78-C questionnaire for asthma diagnosis in children under 13 years of age. Braz Ped News. 1999;1:3-5.

8. Polgar P, Promadhat V. Pulmonary testing in children. Philadelphia USA: WB Saunders; 1971. p. 100-153.

9. Gaffin JM, Shotola NL, Martin TR, et al. Clinically Useful Spirometry in preschool aged children: Evaluation of the 2007 American Thoracic Society Guidelines. J Asthma. 2010;47(7):762-767.

10. Costa D, Gonçalves H, Lima L, et al. Novos valores de referencias para pressões respiratórias máximas na população brasileira. J Bras de Pneumol. 2010;36(3):306-312.

11. Simoes RP, Deus AP, Auad MA, et al. Pressões respiratórias máximas em indivíduos saudáveis sedentários de 20 a 89 anos da região central do Estado de São Paulo. Rev Bras Fisioter. 2010;14(1):60-67.

12. WHO. AnthroPlus for personal computers Manual: Software for assessing growth of the world's children and adolescents. Geneva, Switzerland; 2009.
13. American Thoracic Society/European Respiratory Society. ATS/ERS statement on respiratory muscle testing. Am J Respir Crit Care Med. 2002;166(4):518-624

14. Badr C, Elkins MR, Ellis ER. The effect of body position on maximal expiratory pressure and flow. Aust J Physiother. 2002;48(2):95-102.

15. Souza RB. Pressões respiratórias estáticas máximas. J Pneumol. 2002;28(Suppl 3):S155-S165.

16. Heinzmann-Filho JP, Vasconcellos Vidal PC, Jones MH, et al. Normal values for respiratory muscle strength in healthy preschoolers and school children. Respir Med. 2012;106(12):1639-1646.

17. Enright PL, Kronma R, Manollo TA, et al. Respiratory muscle strength in the elderly. Correlates and reference values. Am J Respir Crit Care Med. 1994;149(2 Pt 1):430-438.

18. Domenech-Clar R, Lopez-Andreu JA, Compte-Torrero L, et al. Maximal static respiratory pressures in children and adolescents. Pediatr Pulmonol. 2003;35(2):126-132.

19. Matecki S, Prioux J, Jaber S, et al. Respiratory pressures in boys from 11-17years old: a semilongitudinal study. Pediatr Pulmonol. $2003 ; 35(5): 368-374$

20. Silva SB, Viana ESR, Sousa MBC. Changes in peak ventilatory flow and respiratory strength during the menstrual cycle. Respir Physiol Neurobiol. 2006;150:211-217.

21. Blimkie CJ. Resistance training during pre- and early puberty: efficacy, train.ability, mechanisms, and persistence. Can J Sport Sci. 1992;17(4):264-279.

22. Pratt M. Strength, flexibility, and maturity in adolescent athletes. Am J Dis Child. 1989;143(5):560-563.

23. Freitas DA, Borja RO, Ferreira GMH, et al. Equações preditivas e valores de normalidade para pressões respiratórias máximas na infância e adolescência. Rev Paul Pediatr. 2011;29(4):656-662.

24. Gaultier C, Zinman R. Maximal static pressures in healthy children. Res pir Physiol. 1983;51(1):45-61.

25. Black LF, Hyatt RE. Maximal respiratory pressures: normal values and relationship to age and sex. Am Rev Respir Dis. 1969;99(5):696-702.

26. Cook CD, Mead J, Orzalesi MM. Static volume pressure characteristics of the respiratory system during maximal efforts. J Appl Physiol. 1969; 19:1016-1022.

27. Merkus PJ, ten Have-Opbroek AA, Quanjer PH. Human lung growth: a review. Pediatr Pulmonol. 1996;21(6):383-397. 